\title{
SENTIDOS DEL AUDIOVISUAL SEGÚN ALGUNAS ORGANIZACIONES SOCIALES REGIONALES Y SEGÚN

\author{
ALGUNAS POLÍTICAS \\ ESTATALES NACIONALES:
}

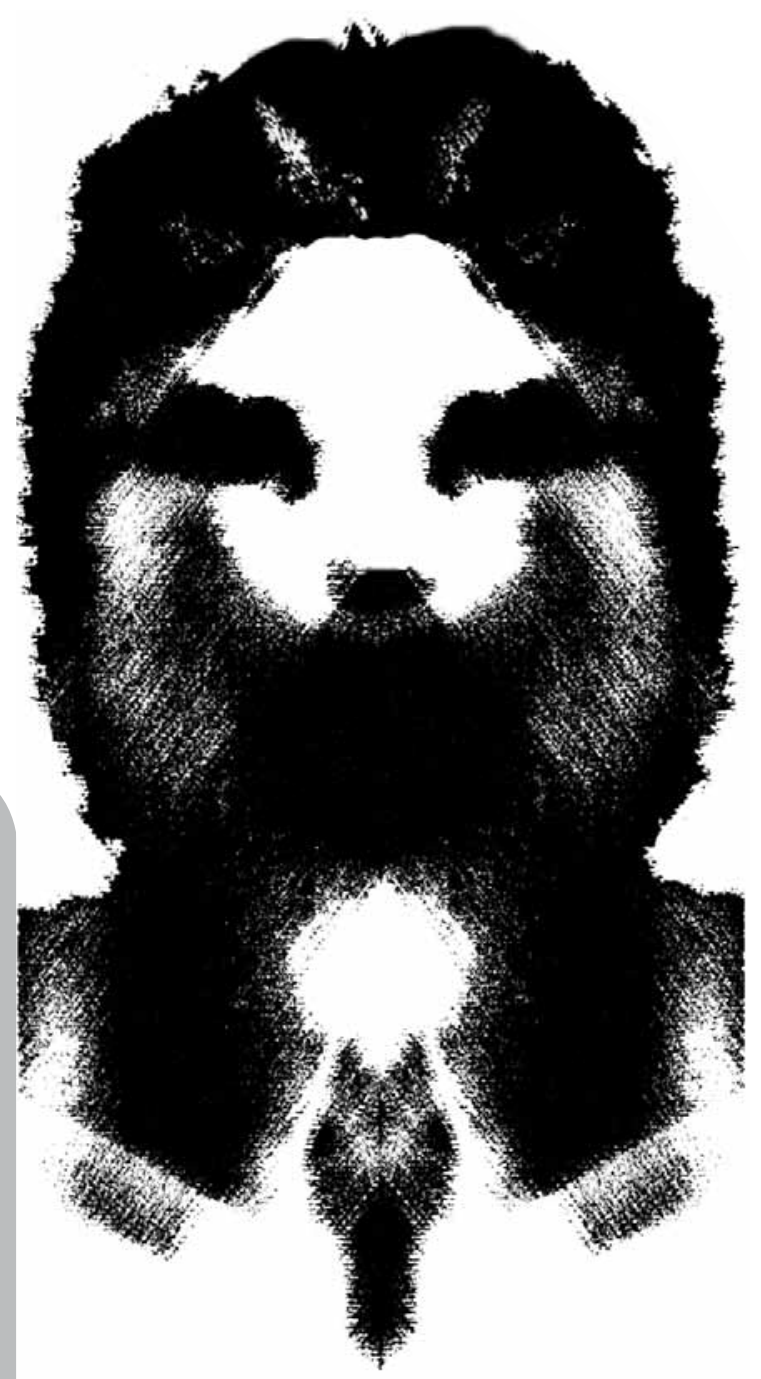

EMPALMES Y DESENCAJES

Por:

Camilo Aguilera

Profesor Escuela de Comunicación Social, facultad de Artes Integradas

Universidad del Valle

leratoro@yahoo.com.br

Gerylee Polanco

Comunicadora Social

gerylee23@hotmail.com

\section{Resumen}

El siguiente artículo hace parte de la investigación Experiencias colectivas de auto-representación cultural a través del uso de tecnologías audiovisuales en Nariño, Cauca y Valle del Cauca, financiada por el Ministerio de Cultura de Colombia, la Escuela de Comunicación Social de la Universidad del Valle y la Agencia Española de Cooperación Internacional para el Desarrollo/AECID. El propósito de esta investigación es servir de base empírica para enriquecer el ejercicio de cualificación del Plan Audiovisual Nacional/PAN, política que desde el año 2008 impulsa el Ministerio de Cultura. Esta investigación, aún no finalizada, comprende mucho más de lo que en este artículo recogemos; aquí hemos incluido sólo algunos aspectos generales sobre el diseño metodológico de la investigación y sobre los referentes teóricos de los que partimos, al igual que algunos de los resultados del estudio que giran en torno a los sentidos que ciertas organizaciones sociales que usan tecnologías audiovisuales atribuyen a éstas y a los propósitos colectivos a las que las vinculan. Sentidos y propósitos son justamente los resultados que incluimos en este artículo, además del ejercicio de contrastarlos con los sentidos y propósitos que el estado colombiano, en los documentos oficiales que dan cuenta del PAN, atribuye a estas tecnologías.

Palabras-clave:

tecnologías audiovisuales, organizaciones sociales, estado, significados sociales 


\section{Estrategia metodológica}

Metodológicamente, la investigación acude, al menos parcialmente, a dos modelos que aquí ensayamos su complementariedad: de un lado, el propuesto por Pierre Bourdieu a través del concepto de campo, una de cuyas características sería el despliegue a su interior de una lucha entre los diferentes actores y organizaciones que lo integran por detentar el monopolio de la definición 'legítima' de aquello que constituye su especificidad, para nuestro caso lo audiovisual. El segundo modelo es el de la antropología comprensiva que propone identificar los significados sociales que "los actores sociales asignan (...) a situaciones, a otras personas, a las cosas y a sí mismos" (Tylor y Gogdan: 24). Estos "significados son productos sociales" (Ídem), esto es, histórica y culturalmente determinados. ¿Qué significados de lo audiovisual son producidos, re-producidos, circulados, apropiados o impugnados? A partir de la respuesta a este interrogante -creemos- es posible articular la tradición comprensiva/interpretativa de las ciencias sociales (Max Weber, Clifford Geertz) con el enfoque sociológico propuesto por Pierre Bourdieu, específicamente cuando éste se pregunta por las "luchas donde se producen los sentidos” (2005: 433). Más que producto de una suerte de 'subjetividad espontánea' de los actores sociales, la propuesta de Bourdieu apunta hacia la necesidad de captar tales sentidos en la lucha de la que son objeto. Una de las tareas de la investigación es, pues, no solo lograr 'atrapar' los sentidos imputados al audiovisual, sino también y a través suyo, lograr identificar las disputas que tienen lugar por el "monopolio de la legitimidad" (Ídem: 252) de tales sentidos. Implementando el modelo metodológico aquí esbozado, obtuvimos dos de los resultados más importantes de la investigación: un 'mapa' de los actores y organizaciones sociales indagadas, incluido el estado, acerca de los sentidos de su actividad audiovisual y la contrastación de los significados sociales recogidos en el 'mapa' y la identificación de las convergencias y divergencias entre éstos. Justifica este ejercicio de contraste la necesidad de poner en diálogo y debate las diversas perspectivas halladas, buscando ofrecer pistas que permitan hacer mayor empalme entre las expectativas, intereses y sensibilidades de las organizaciones y las del estado respecto del audiovisual.
Operativamente, nuestra estrategia metodológica tiene dos componentes: uno extensivo y otro intensivo. El primero incluye un inventario de organizaciones audiovisuales de Nariño, Cauca y Valle del Cauca y una encuesta aplicada a una porción de las organizaciones identificadas en el inventario. Las informaciones recogidas en ambos ejercicios permiten hacer generalizaciones en cuanto a aspectos cuantitativos del fenómeno estudiado y, además, fueron de suma utilidad para hacer una selección más cualificadas de las ocho organizaciones estudiadas. La siguiente es una pequeña muestra de los resultados obtenidos en el Inventario y en la Encuesta:

- La mayoría de organizaciones tienen como campo de acción las ciudades grandes e intermedias. Esto último lo comprueba que la mayor concentración de estas organizaciones se presenta, en un primer nivel, en Cali, Pasto y Popayán y, en un segundo nivel, en Buenaventura, Palmira y Buga (ciudades del Valle del Cauca).

- Existe un número significativo de pequeñas poblaciones en las que han surgido organizaciones sociales que vienen usando lo audiovisual. Se trata de, al menos, 22 localidades: seis en Nariño (Pupiales, Tangua, La Unión, Túquerres, Cumbal y Samaniego), ocho en el Cauca (Sucre, Almaguer, Lerma, Patía, Silvia, Piendamó, Guapi y Tierradentro) y también ocho en el Valle del Cauca (La Unión, Calcedonia, Anserma, Toro, Sevilla, Andalucía, La Victoria y Restrepo, sin tener en cuenta poblaciones semi-rurales, algunas de ellas en muchos sentidos integradas a Cali como Jamundí y Candelaria).

El componente metodológico intensivo incluye el uso de técnicas de investigación propias de la etnografía: la entrevista semi-estructurada en profundidad (conversación, en clave etnográfica) a los integrantes de las organizaciones, la observación en campo de las dinámicas cotidianas de las organizaciones y el análisis de los materiales audiovisuales producidos por las organizaciones y de algunos documentos-clave producidos por el Estado en materia audiovisual.

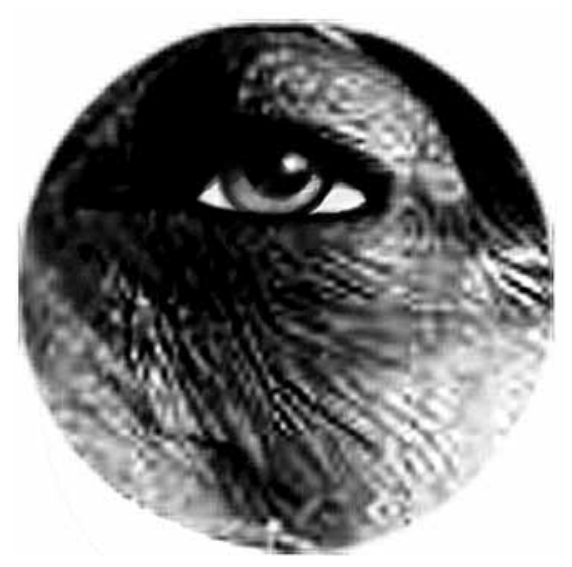


Como decíamos antes, a partir del inventario y la encuesta fue posible seleccionar con mayor criterio las organizaciones contempladas para el componente intensivo de la investigación.

La selección se realizó cruzando diversas variables de análisis, así:

1. Modalidades de trabajo audiovisual: a) Procesos de realización audiovisual;

b) Procesos de formación en realización audiovisual; c) Procesos de formación de públicos audiovisuales

2. Departamento en que actúa la organización social: a) Nariño; b) Cauca; c) Valle del Cauca

3. Tipo de asentamiento humano en que se desenvuelve la organización social:

a) Urbano; b) Rural

4. Contexto geográfico en el que se desenvuelve la organización social:

a) Zona andina; b) Zona interandina (valle); c) Zona de litoral

5. Perfil étnico predominante de la comunidad en que actúa la organización social:

a) Población afro-descendiente; b) Población indígena; c) Población mestiza.

La definición de estas variables de análisis busca recoger la mayor diversidad posible de informaciones en cuanto al tipo de organización social estudiada y al trabajo audiovisual desarrollado. Cruzando estos grupos de variables de análisis y tomando como insumo los resultados arrojados en el estudio extensivo, nos propusimos la indagación sobre las siguientes organizaciones:

- El Medio (Pasto, Nariño): Organización que impulsó la creación y se encuentra a cargo de la realización del Festival Internacional de Cine de Pasto.

- Corpo-imagen (Sucre, Cauca): Pequeña organización rural del Macizo Colombiano que produce documentales y ficciones sobre mitos, leyendas, fiestas, eventos y músicas locales.

- Tejido de Comunicación de la Asociación de Cabildos Indígenas del Norte del Cauca/ACÍN (Santander de Quilichao, Cauca): Organización que implementa una estrategia de comunicación que vincula tecnologías de comunicación (impresos, radio, internet y video) con medios de movilización política como las asambleas y las mingas.

- González Urrutia Films (Villapaz-Jamundí, Valle del Cauca): Experiencia prolífica y aficionada de producción de ficciones y documentales de larga duración sobre diversos temas, dentro de los que se destacan prácticas culturales (el bunde, el chumbe, la brujería, etc.) ligadas a cierto universo de creencias mágico-religiosas afro. Se trata de la producción de 12 películas en dos años de existencia de la organización.

Yubarta Televisión (Cali, Valle del Cauca): Canal de televisión de la Universidad del Pacífico que trabaja desde el paradigma étnico, local y de la inclusión social. Sus miembros son, en su mayoría, egresados de la Escuela de Comunicación Social de Univalle.

- Colectivo Mejoda (Cali, Valle del Cauca): Organización del Distrito de Aguablanca que creó y realiza el Festival Nacional del Cine y Video Comunitario. Se dedica a la producción de documentales centrados en los jóvenes del Distrito y ha impulsado procesos de capacitación en el mismo sector.

- Casa Occio (Cali, Valle del Cauca): Experiencia de producción de televisión para internet liderada por jóvenes interesados en las TIC. Orienta su trabajo una concepción de libre acceso a este tipo de tecnologías.

- Fundación Mujer, Arte y Vida/MAVI (Cali, Valle del cauca): Organización feminista que se apropia de diferentes tecnologías de comunicación, entre éstas el video, buscando posicionar y movilizar 'demandas de género' en las agendas política y mediática locales y nacionales. 
El componente intensivo de la investigación implicó que la recolección de la información se efectuara buscando introducirse en las dinámicas de trabajo cotidianas de las organizaciones, centrándose en tres aspectos:

1. Las organizaciones: Identidad/alteridad de las organizaciones: referentes (lo emulable) y anti-referentes (lo impugnable); procesos históricos/culturales/políticos gracias a los cuales la formación y el desarrollo de la organización tuvieron lugar; luchas de representación simbólica en que las organizaciones se inscriben; relaciones de la organización con su entorno inmediato: capacidad de éstas para establecer alianzas con otras organizaciones y de capitalizar las dinámicas locales, regionales o nacionales del campo cultural; metas, objetivos y sueños colectivos; autovaloración del trabajo; estrategias de financiación; etc.

2. El proceso de apropiación tecnológica: Procesos históricos/sociales/culturales por los cuales las organizaciones llega a apropiarse de las tecnologías audiovisuales; antecedentes de la relación de las organizaciones con otras tecnologías de la imagen; funciones y significados atribuidos a estas tecnologías; etc.

3. La actividad audiovisual: conflictos/temas/asuntos del contexto local que las organizaciones recogen en su trabajo audiovisual; diálogo del contexto local con otros más amplios (regionales, nacionales y/o globales); estéticas audiovisuales; homogeneidad/heterogeneidad ideológica y formal; procesos de producción, productos audiovisuales y procesos de circulación de los productos; relación de éstos con los públicos; división del trabajo y relaciones de poder en el desarrollo de las actividades audiovisuales; roles audiovisuales; percepciones de las organizaciones sobre el campo audiovisual local y nacional y sobre las políticas estatales en el área audiovisual.

\section{Referentes teóricos}

Hemos partido de varios conceptos: de un lado, el de movimientos sociales. Como sabemos, los movimientos sociales contemporáneos no son exclusivos de organizaciones cuyas reivindicaciones sean exclusivamente de orden político o económico (Álvarez, Dagnino y Escobar); también la cultura y la comunicación son ámbitos en los que los movimientos sociales actúan y formulan demandas no siempre de manera explícita ni plenamente conscientes. Si un movimiento social se define por la posición antagónica que adopta en las relaciones de dominación hegemónicas de una sociedad, deberemos aceptar que muchas de las organizaciones sociales de la región, implícita o explícitamente, ponen en cuestión lo que podríamos denominar, al menos tentativamente, relaciones de comunicación de una sociedad. La producción de imágenes por parte de las organizaciones sociales implica, pues, la afirmación de diversos nosotros cuya motivación es, en no pocas ocasiones, controvertir o 'corregir' las representaciones de las que son objetos por instancias sociales hegemónicas como el Estado y el gran mercado nacional o multinacional audiovisual (ya sea cinematográfico, televisivo, videográfico o de internet). Se trata, por tanto, de organizaciones que participan directamente en las luchas de representación simbólica que se traban en una sociedad, de luchas en las que se confrontan, imponen y negocian significados contrarios de la realidad social. El Tejido de Comunicación de la ACÍN, por ejemplo, defiende un significado del movimiento indígena del Cauca diametralmente opuesto al que predomina en las representaciones periodísticas y estatales. En este caso, la acción colectiva se realiza en y por medio de la comunicación; acción que es afirmación de una palabra y una imagen, de una memoria e identidad colectiva, reclamando para sí una suerte de 'derecho de auto-representación'.

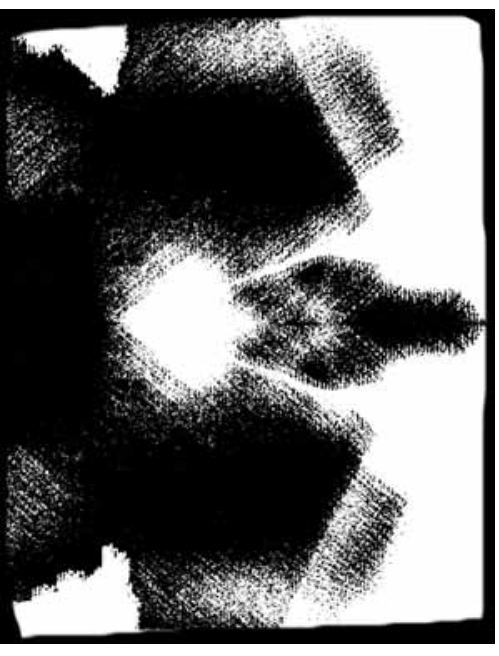

Otro concepto desde el que proponemos analizar nuestro objeto de investigación es el de consumo, definido desde algunas corrientes teóricas como un proceso social de apropiación y uso, de significación y re-significación (De Certeau, García-Canclini, Martín-Barbero, etc.). Como muestra el estudio, es significativo el volumen, en la región, de procesos colectivos y organizativos de consumo/uso/apropiación de tecnologías de la comunicación, lo que matizaría un fenómeno que a veces se presenta como dominante según el cual el consumo sería una actividad cada vez más individualizada (el paso de la televisión localizada en la sala de los hogares para consumo de toda la familia a varios televisores o computadores cada uno situado en cada uno de las habitaciones de la casa es un ejemplo paradigmático). Así como el consumo aparece como una acción colectiva también lo son los sentidos que se desprenden de su actividad a partir del uso de máquinas que producen símbolos. Por tanto, dar cuenta de los usos sería dar cuenta de los usuarios y su particularísima relación con las tecnologías de comunicación. Tal es el intento desarrollado, en niveles de profundidad diferenciados, con los estudios intensivos. 
Anclada a esta acepción de la noción de consumo como uso y apropiación, cobra relevancia el concepto de mediaciones (Jesús Martín-Barbero) para entender los procesos de comunicación: cultura e historia constituirían la densidad irreductible del usuario. Éste sería, pues, un agente o grupo social histórica y culturalmente constituido, denso y esta espesura haría inevitable la emergencia de multiplicidad de formas de apropiación de las tecnologías de comunicación. Como Raymond Williams y Jesús Martín-Barbero, entendemos que ni el análisis de la tecnología ni el análisis de la comunicación pueden hacerse al margen del análisis de la cultura. Hacerlo sería incurrir en anacronismos y asimetrías entre las tecnologías de una sociedad y los procesos históricos, culturales y sociales que hicieron posible su surgimiento (vía invención o apropiación), su desarrollo y sus mismas formas de uso. La tecnología y la comunicación son, por definición, fenómenos sociales, esto es, histórica y culturalmente determinados en la relación de los unos y los otros. Por ser sociales, entonces, exigen que se estudie el uso de la tecnología audiovisual en el contexto de la cultura que la produce o la apropia. De esto que nos hayamos detenido en las trayectorias colectivas de las organizaciones estudiadas y en los procesos que explican su desarrollo y, dentro de éste, su apropiación de tecnologías de comunicación como las audiovisuales.

Por último, reconociendo que las organizaciones con las que trabajamos son no sólo audiovisuales, mas de comunicación, creemos que es de gran utilidad el concepto de convergencia digital o tecnológica que apunta a un fenómeno cada vez más acentuado: la articulación entre tecnologías de comunicación diversas y, especialmente, las articulaciones entre video e internet.

\section{Algunos resultados}

Este apartado constituye apenas una muestra de los resultados de la investigación, centrándonos en el ejercicio de contrastar los sentidos atribuidos al audiovisual por el estado colombiano, específicamente en su política PAN, con los sentidos imputados por las organizaciones. En mayor o menor medida, las organizaciones sociales audiovisuales estudiadas definen el audiovisual en el siguiente marco de sentidos, cada uno de los cuales expresa un motivo que justifica su uso:

1. Impugnación de las representaciones de las que las comunidades han sido objeto por parte de otros, especialmente los medios periodísticos hegemónicos: "Aquí (...) llegan documentalistas y quieren grabar cómo son los nasa, cómo son sus rituales, qué comen, cómo se visten, y si están en una moto o un carro, pues 'mejor nos los grabemos; mejor vamos al resguardo a grabar sus vestidos ancestrales, que ojalá no aparezca nada de tecnología’ ¡Como si fuéramos culturas muertas! (...) Los medios de comunicación (...) quieren mostrarnos por allá, los 'aborígenes', pero no muestran que somos una cultura con un plan de vida y con una propuesta política, social” (Mauricio Acosta, Tejido de Comunicación, Santander de Quilichao, Cauca).

2. Auto-reconocimiento las comunidades. Se trata de una acción de representación de la comunidad de la que la organización hace parte y de la que resulta la construcción de una imagen de sí. Aquí suelen ser recurrentes las alusiones a términos como 'identidad', 'identidad colectiva' o 'lo que somos', y los temas tratados suelen corresponder a modos de ser colectivos (costumbres, prácticas culturales, etc.), manifestaciones simbólicas comunes (danzas, músicas, formas de hablar y de vestirse, etc.), recursos naturales, valores culturales locales, etc. A propósito de este motivo que justificaría el uso del audiovisual, las organizaciones hablan de "lo que somos, nuestra identidad, nuestros saberes ancestrales, nuestra manera de ser y estar en este territorio nariñense" (Emilio Correa, participante local del V Festival Internacional de Cine de Pasto, Pasto, Nariño). En el caso de otra organización, lo audiovisual aparece asociado a la acción del uso del espejo: "Lo audiovisual permite que uno se encuentre; es como un espejo con el que uno valora lo que tiene" (Víctor González, González Urrutia Films, Villapaz, Valle del Cauca).

3. 'Hacer comunidad' y 'ciudadanía'. Aquí importa, como en el motivo número 2, que la comunidad se autoreconozca, pero admitiendo, al menos implícitamente, que para tal es necesario (también) construirla o fortalecerla. Por ejemplo: los documentos que dan cuenta del sentido de Yubarta Televisión (Buenaventura, Valle del Cauca) hablan del audiovisual como un medio de "construcción y fortalecimiento de tejido social”. Daney Mina, el director de este canal, habla de "construir (...) unidad y construir comunidad porque ese es nuestro horizonte: avanzar en construir comunidad". Así, al asignar un papel al audiovisual en tal propósito, las imágenes que resultan del uso de esta tecnología no sólo hablan de 'lo que somos', sino también de 'lo que queremos ser', esto es, 'lo que aún no somos del todo': “ayudar a los jóvenes a despertar más su ser como ciudadano, como actor político, como actor social, cultural" (Ricardo Chamorro, Mejoda, Cali, Valle del Cauca).

4. Evocación de parte del pasado de las comunidades. Al asignar esta función al audiovisual suelen ser utilizados términos como 'memoria' y 'memoria colectiva' y expresiones como "mostrar de donde venimos" (Víctor González, González Urrutia Films). El siguiente testimonio también atestigua el interés por el origen de la comunidad y, entonces, de un tipo de audiovisual capaz de mostrar "cómo la gente (...) en los barrios donde vivimos narra las cosas de los pueblos de donde vienen" (Víctor Palacios, Mejoda, Cali, Valle del Cauca). 
5. Visibilización de conflictos y problemáticas locales, reflexión sobre éstas y movilización de la comunidad hacia su solución. A diferencia de los motivos 2 y 3, la imagen que resulta de esta operación admite que los problemas y conflictos, al igual que las acciones tendientes a resolverlos o tratarlos, también constituyen la identidad de las comunidades. Así, importa 'lo que somos y valoramos' (como en el motivo 2 en su interés, por ejemplo, por las fiestas, las danzas, los modos de ser colectivos, etc., en fin, las cosas positivas de la comunidad), como también importa, y en este caso sobre todo, 'cómo estamos' y 'qué hacemos para estar de otra manera'. De allí que Víctor González (González Urrutia Films, Villapaz, Valle del Cauca) afirme que una de las razones que lo llevó a hacer una de sus películas fue "mostrar (...) que (...) se comete mucha injusticia con los trabajadores de aquí". De otro lado, como decíamos, importa visibilizar los conflictos y problemas locales, pero también reflexionar en torno a ellos: "el video $(\ldots)$ se piensa $(\ldots)$ como (...) un producto reflexivo sobre hechos particulares" (Mauricio Acosta, Tejido de Comunicación, Santander de Quilichao, Cauca). Además de la reflexión y la concientización sobre ciertos conflictos, importa las soluciones que la propia comunidad propone para superarlos. De allí que "se trata de visibilizar proyectos" (Marcela Durán, Casa Occio, Cali, Valle del Cauca) y que "lo que interesa es que la pieza (audiovisual) movilice” (Víctor Palacios, Mejoda, Cali, Valle del Cauca).

Frente a estos sentidos del audiovisual, proponemos ahora una revisión rápida de los significados atribuidos a éste en la política PAN. Como se verá, existen diferencias, pero también, especialmente en el año 2010, similitudes de sentido:

En el año 2008, el Ministerio de Cultura lanza su Plan Audiovisual Nacional-PAN, una política que recoge algunos de los programas desarrollados por la Dirección de Cinematografía del Ministerio de Cultura desde su creación: Cine en el Cerebro Social, Imaginando Nuestra Imagen, Vacunación contra la Amnesia Audiovisual y Las Maletas de Películas. Según documentos que recogen el proceso de formación de la Dirección, ésta, desde entonces, "se planteó el reto de contribuir en la construcción de una geografía audiovisual del país, más allá de la que tradicionalmente se conoce desde Cali, Medellín, Bogotá y el Caribe. Se trataba de estimular hechos audiovisuales en cuya narración puesta en imagen se manifestaran los diversos relatos locales, como una suerte de cartógrafos sociales que trazan la geografía cultural del país diverso, multiétnico y pluricultural y sus transformaciones dialogantes entre si" (Ministerio de Cultura: 2001:2). El PAN, como los mencionados programas que lo preceden, ha sido una política de tipo regional y dirigido a comunidades que desarrollan trabajo audiovisual en estándares no necesariamente profesionales. Desde la creación del PAN se incluyó en el mismo una línea de estímulos económicos para el desarrollo de proyectos audiovisuales asignados según convocatoria pública de méritos. Estas convocatorias, salvo un caso que precisaremos más adelante, se integraron a las del Programa Nacional de Estímulos, creado en el año 1997, bajo la etiqueta Estímulos a la labor cinematográfíca-Plan Nacional Audiovisual. En los documentos de estas convocatorias es posible rastrear los sentidos que el Ministerio ha atribuido al PAN y tal es uno de los ejercicios que hemos hecho, cuyos resultados presentamos a continuación. En el año 2008, el PAN es definido “como una estrategia para fortalecer la cultura audiovisual en el país. Apoya la investigación, la realización de obras audiovisuales, la formación de nuevos realizadores, la circulación de obras audiovisuales y la preservación del patrimonio audiovisual" (Ídem: 2008a: 93.). En el mismo año de 2008, el PAN lanza por primera y única vez una convocatoria independiente del Portafolio de Estímulos, denominada Apropiación de la cultura audiovisual y digital ${ }^{1}$.

El objetivo declarado de la convocatoria afirma el carácter regional y comunitario del PAN: "A través de esta convocatoria el Ministerio reconoce las experiencias en curso e incentiva nuevas iniciativas para que las comunidades puedan verse, pensarse y contarse a sí mismas y a otros" (Ídem, 2008c: 4). Esta convocatoria incluyó tres líneas: a) desarrollo de proyectos de formación en producción audiovisual, realización audiovisual y exhibición de video comunitario; b) desarrollo de proyectos que promovieran el uso de las tecnologías de la información y la comunicación (TIC); y c) adquisición de material audiovisual regional para la creación la Colección Audiovisual del PAN.

En la documentación revisada que ha producido el Ministerio a propósito del PAN, la convocatoria de Apropiación es la primera y la única que introduce el término video comunitario, reconociendo, de algún modo, la existencia de un campo distinto al cinematográfico o al televisivo. Una posible evidencia de este reconocimiento es que el PAN postule criterios de evaluación de los proyectos participantes muy distintos a los aplicados en otras de sus convocatorias. Mientras en esta convocatoria del PAN se indica dentro de sus criterios de evaluación los "elementos de contexto e impacto en la comunidad" (Ídem: 9) o "la generación de inclusión social" (Ídem: 16), en las convocatorias del Fondo para Desarrollo Cinematográfico (FDC) se señala como criterios de evaluación la "aspectos artísticos, técnicos y conceptuales" y los “económicos” (Ídem, 2008d: 13) de los proyectos participantes. En la caracterización hecha sobre el material que el Ministerio buscaba adquirir para la formación de la Colección Audiovisual del PAN se indican en los criterios de evaluación los aspectos socio-culturales y hasta políticos del trabajo audiovisual de las organizaciones comunitarias, ampliando así las valoraciones sobre los aspectos artísticos, técnicos y estéticos. Así, los materiales que serían escogidos para la Colección debían "aportar a la representación de la diversidad étnica, cultural, religiosa y política del país" o "aportar a la reflexión sobre la historia colombiana, sus conflictos y sus realidades socioculturales" ( Ídem, 2008c: 19). En suma, a juzgar por esto, la convocatoria de Apropiación del PAN en el año 2008 se centró más en los aportes sociales de 
los proyectos audiovisuales que apoyó que en las bondades artísticas o la solidez financiera de los mismos.

Un aspecto que hemos pasado por alto en este análisis de la documentación pública que habla del PAN durante el año 2008 tiene que ver con el sentido imputado a lo audiovisual en la primera de las convocatorias de ese año: en ella-como veíamos atrás- el Ministerio habla de "fortalecer la cultura audiovisual en el país" (Ídem, 2008a: 93.). Dos inferencias es posible hacer de esta afirmación: la primera es que lo audiovisual es concebido como cultura y, para ser más precisos, como una cultura. La segunda inferencia es que tal cultura sería débil en los sectores comunitarios del campo audiovisual o al menos no tan fortalecida como en otros sectores. Lo que niega esta concepción del audiovisual es, por obvio que parezca decirlo, la existencia de diversas culturas audiovisuales, lo que contrasta con la concepción de cultura que la propia política defiende y promueve cuando habla de "geografía cultural del país diverso, multiétnico y pluricultural” (Ídem, 2001: 2). Así, mientras la política habla de culturas al referirse a la gente que usa el audiovisual, sólo habla de cultura al referirse a los modos de hacer imágenes a través de este medio. La concepción amplia de cultura, claramente inspirada en el paradigma de la multi-culturalidad, no admite, sin embargo, la posibilidad de diversidad de culturas audiovisuales; reconoce una sola y propone democratizar su acceso. Cuál es esta cultura no es una pregunta que el PAN responda en la documentación consultada, pero es plausible suponer que se trata de aquella ya consagrada por los pensum universitarios, la literatura especializada y la práctica audiovisual profesional: "lenguaje cinematográfico", "géneros”, "tipos de planos”, "puntos de giro dramático”, etc.

En el año siguiente, 2009, el PAN sigue integrado al Programa Nacional de Estímulos, bajo el nombre Estímulos a la labor cinematográfica y audiovisual regional - Plan Audiovisual Nacional, no obstante, dentro del paquete de estímulos no se integraron las modalidades de la convocatoria de Apropiación y su énfasis al fomento del video comunitario. En el Programa Nacional de Estímulos de 2009, el PAN es definido como “una política de fomento regional de experiencias cinematográficas y audiovisuales, complementaria a las políticas dirigidas al desarrollo profesional e industrial del cine en Colombia” (Ídem, 2009: 95). Como vemos, se re-afirma en el PAN su carácter de política dirigida a las regiones y a sectores del campo audiovisual no industriales ni profesionales, aunque paradójicamente incluye lo cinematográfico, un sector del campo audiovisual para el que lo industrial y lo profesional son criterios importantes de su trabajo audiovisual. Como también es posible ver, el PAN es definido como política complementaria, definición ausente en la convocatoria del año 2008.

En el año 2010, la convocatoria del PAN se integra nuevamente a la del Programa Nacional de Estímulos. Para esta versión, desaparece la modalidad de formación Imaginando Nuestra Imagen y demás modalidades que fomentaban la producción de obras audiovisuales en las regiones. En el texto de presentación se indica lo siguiente acerca del PAN: "Desde la construcción del Plan Nacional de Cultura 2001-2010, el sector audiovisual expresó la necesidad de ampliar la participación y fortalecer la creación y la memoria colectiva a través de las imágenes en movimiento. En concordancia con esta realidad la Dirección de Cinematografía del Ministerio de Cultura formuló el Plan Audiovisual Nacional (...) que fundamentado en los principios de descentralización y multiculturalidad, busca potenciar los atributos de los medios audiovisuales y cinematográficos para registrar, preservar y circular contenidos generados desde las comunidades a nivel local. En este sentido el PAN ha permitido complementar las políticas que operan desde el Fondo para el Desarrollo Cinematográfico (...) y que están dirigidas a fortalecer la industria del cine en Colombia” (Ídem, 2010c: 97). Como es posible ver, en el año 2010 se reitera, respecto del año anterior, la idea del PAN como política regional y complementaria de las políticas de industrialización del cine nacional. Por otro lado, se recuperan términos de la convocatoria de Apropiación del año 2008 que -como vimos- estaban ausentes en la del 2009: comunidades, nivel local, multiculturalidad, etc.

En el documento Compendio de Políticas Culturales del Ministerio de Colombia, publicado en el año 2010, se indica que "el PAN tiene como objetivo estratégico hacer una apuesta por la diversidad, porque las comunidades puedan ver, pensar y hacer obras audiovisuales y porque este desarrollo de la cultura audiovisual sirva como herramienta de desarrollo social" (Ídem, 2010a: 507). Aunque, como en el 2008, no tiene lugar la idea de diversas culturas audiovisuales, la definición del PAN en el 2010, al menos en términos discursivos, amplía significativamente los sentidos de esta política, asociando dicha cultura audiovisual al concepto de desarrollo social, término inédito en los documentos que definen el PAN en los años 2008 y 2009.

El Compendio señala además que "el PAN ha contado con la participación de organizaciones y colectivos que en su quehacer contemplan el uso del audiovisual, ya sea con fines estéticos o con fines sociales. El audiovisual ha sido para los participantes una herramienta para desarrollar procesos de índole comunicativa, social, cultural, educativa y artística. Las comunidades han visto en las imágenes en movimiento, un mecanismo de autorepresentación, memoria, reconocimiento, construcción de identidad y de ciudadanía activa. En ese sentido, el audiovisual, por su impacto mediático, se ha constituido en una ventana para dar a conocer el sentir y el pensar de ciertas comunidades" (Ídem, 2010a: 520). Fines sociales, procesos de comunicación, procesos sociales, culturales y educativos, auto-representación de las comunidades, memoria, reconocimiento, construcción de identidad y ciudadanía activa son términos novedosos en la definición del PAN. El concepto de auto-representación de las comunidades es interesante pues -creemos- va más allá de lo que tradicionalmente se ha dicho sobre el audiovisual como mecanismo para el fortalecimiento de la memoria y la identidad colectivas. Otro aspecto novedoso tiene que ver con la idea de 
proceso audiovisual y no sólo de producto u obra audiovisual, términos regularmente usados en las convocatorias del Ministerio. Esto implica recocer una dimensión del trabajo audiovisual que para muchas de las organizaciones indagadas es fundamental y que no necesariamente se hace visible en las piezas audiovisuales que producen. Las organizaciones -según nuestra investigación- suelen llamar proceso a esta dimensión del trabajo audiovisual que tiene que ver, en muchos casos, con lo que las personas que participan aprenden tanto en términos audiovisuales como con relación a los temas tratados.

Mirando retrospectivamente los sentidos atribuidos por el Ministerio de Cultura al PAN, podríamos hablar, especialmente en el año 2010, de una concepción cada vez más social de esta política. Este desarrollo conceptual, sin embargo, no se ve expresado en la asignación presupuestal de las estrategias del PAN. En el año 2009, por ejemplo, para la convocatoria del PAN se asignaron 1.746 millones de pesos mientras que se asignaron 4.910 millones de pesos a la convocatoria del FDC, lo que evidencia un acento del Ministerio en la promoción del sector cinematográfico . Más allá de que, evidentemente, producir cine es más oneroso que producir video, esta diferencia presupuestal entre las convocatorias del PAN y el FDC tal vez sea posible interpretarla como resultado de una concepción acerca de las imágenes en movimiento, según la cual prepondera el valor simbólico atribuido al cine, y en especial a los largometrajes de ficción, que al video producido por pequeñas comunidades para las que el lucro económico y el lucro en términos de prestigio artístico no son prioritarios.

Como advertimos antes, los datos y el ejercicio de análisis aquí propuesto es parte de una investigación de resultados más amplios. La investigación se encuentra en proceso y sus resultados finales se presentarán en un libro cuya edición deberá culminar durante el primer semestre del año 2011

\section{Notas:}

${ }^{1 .}$ Esta convocatoria surge "después de este proceso y conforme a los resultados de este piloto denominado Imágenes \& Imaginarios" (Ídem, 2008b: 5) y, por tanto, "se decide que para dinamizar el PAN es necesario usar un mecanismo de apoyo directo a las propuestas que distintas comunidades emprenden para acercarse a la cultura audiovisual" (Ídem). Esto constata que esta convocatoria estuvo dirigida a una población distinta a la del Fondo de Desarrollo Cinematográfico (FDC).

2. También es de notar que dentro de las diferentes políticas del Ministerio, el Plan Nacional de Recuperación de Centros Históricos y el Plan Nacional de Música para la Convivencia son los que cuenta con mayor presupuesto anual dentro de los recursos que maneja el Ministerio (por encima de los 10 mil millones de pesos cada una).

${ }^{3 .}$ Es de anotar que la Dirección de Comunicaciones del Ministerio de Cultura, junto a la Comisión Nacional de Televisión y a RTVC, son las autoridades estatales a cargo del manejo de todos los temas relativos a la televisión en el país.

\section{Bibliografía}

Tylor, S. y Gogdan, R. Introducción a los métodos cualitativos. La búsqueda de significados. Barcelona, Paidós.

Bourdieu, Pierre (2005). Las reglas del arte. Génesis y estructura del campo literario. Barcelona, Anagrama.

Álvarez, Dagnino y Escobar (2001). Política cultural y cultura política: Una nueva mirada sobre los movimientos sociales latinoamericanos. Taurus.

De Certeau, Michel (2000). La invención de lo cotidiano. México D.F.: Universidad Iberoamericana.

García-Canclini, Néstor (1995). Consumidores y ciudadanos: Conflictos multiculturales de la globalización. Grijalbo. Martín-Barbero, Jesús (2003). De los medios a las mediaciones. Bogotá: Convenio Andrés Bello.

Williams, Raymond (1992). Historia de la comunicación II: De la imprenta a nuestros días. Bosch Casa Editorial.

Ministerio de Cultura (2001). Balance de los programas de Formación Audiovisual de la Dirección de Cinematografía 1998 -2001. Bogotá, Ministerio de Cultura. (2008a). Portafolio de Convocatorias del Programa Nacional de Estímulos a la Creación e Investigación. Bogotá, Ministerio de Cultura.

(2008b). Sistematización de experiencias audiovisuales en Colombia: La experiencia del Plan Audiovisual Nacional. Bogotá, Ministerio de Cultura. (2008c). Convocatoria Apropiación de la Cultura Audiovisual y Digital. Bogotá, Ministerio de Cultura. (2008d). Convocatoria del Fondo de Desarrollo Cinematográfico. Ministerio de Cultura.

(2009). Portafolio de Convocatorias del Programa Nacional de Estímulos a la Creación e Investigación. Bogotá, Ministerio de Cultura.

(2010a). Compendio de Políticas Culturales.

Bogotá, Ministerio de Cultura.

(2010b). Informe de Gestión 2002-2010. Bo-

gotá, Ministerio de Cultura.

(2010c). Portafolio de Convocatorias del Pro-

grama Nacional de Estímulos a la Creación e Investigación. Bogotá, Ministerio de Cultura. 